\title{
Analysis on the Factors Affecting the College and University Students' English Words Pronunciation in Colleges and Universities
}

\author{
Li-na NIU \\ Public English Department, \\ Shengda Trade Economics and Management College of Zhengzhou, \\ Zhengzhou 451191, Henan, China
}

\begin{abstract}
In the process of English acquisition, Chinese as mother tongue exerts an irresistible impact on English phonetics. Data shows that $50 \%$ of undergraduate English majors are disturbed by mother tongue in learning English pronunciation and intonation, while around $80 \%$ of undergraduate non-English majors are affected. Thus, it is found that the reason why the mistakes in English pronunciation and intonation are difficult to correct is that college and university students have been deeply rooted in the native tone, making their ability to distinguish other sound systems reduced. In this paper, how to take relevant measures in learning and better learn English phonetics is further introduced.
\end{abstract}

Keywords: Pronunciation; Factors Analysis; College English; Mother Tongue

\section{Introduction}

Affected by mother tongue, Chinese students, in the process of English learning, receive an irresistible impact from Chinese as mother tongue. Data shows that $50 \%$ of undergraduate English majors are disturbed by mother tongue in learning English pronunciation and intonation, while around $80 \%$ of undergraduate non-English majors are affected. Thus, it is found that the reason why the mistakes in English pronunciation and intonation are difficult to correct is that college and university students have been deeply rooted in the native tone, making their ability to distinguish other sound systems reduced. As American linguist Dr.
Robert Lade pointed out in Contrastive Analysis Hypothesis in 1957, the biggest obstacle to the second language acquisition sourced from the first language (i.e. mother tongue system).

Affected by the traditional exam-oriented education, the education department mainly used written examinations for testing the students' English ability, but seldom tested their oral ability, so that they don't pay attention to English speaking fundamentally. Another important reason why the oral English ability is weak lies in the impact from the traditional learning model. Students are unwilling to spend time on oral practice. Any language is associated with a certain cultural background and cannot exist without the cultural background. Therefore, students cannot really understand the national habits, thinking patterns and values contained in English culture just by language learning. English learning can be promoted only if the western culture is understood to some extent, especially oral English learning. However, in the daily learning, they seldom pay attention to learning the cultural background, and thus, their English speaking is often not native.

Of course, teaching conditions and infrastructure can't satisfy the new education ideas, objectively restricting the oral practice of students. For example, the application of English video and multimedia equipment in English classes will be very helpful for improving students' oral English, and the lectures of foreign teachers can also increase the students' oral English ability, but many schools only assign foreign teachers to English teaching in the department of English, so that the non-English 
majors are hard to come into contact with foreign teachers. At the same time, they are affected by other factors.

\section{The impact from mental factors and cultural standard}

Most students in higher vocational colleges do not lay a solid foundation for fundamental English skills, and many of them even failed to pass English test in the college entrance examination. These students seldom received English training. Thus, they have a small vocabulary and also are poor in reading ability, and many of them cannot accurately pronounce English words and also cannot fluently read sentences as well as an entire text. These students even are incapable of applying a small number of communication expressions such as simple greeting, asking the way, and self-introduction, let alone to communicate in English. Moreover, their grammar foundation is almost zero. All these seriously affect the oral English ability of students. The students to study in higher vocational colleges often feel inferior mentally and do not have a positive attitude toward learning because they are not admitted by their ideal university, and also they often think learning in a higher vocational college is a compelling choice for them. As a result, the huge mental gap leads to depression in their minds and let them have no ambition and motivation in learning, and their mental state toward learning is not sound. Some students don't want to speak English because they are afraid of being criticized by teachers or students and often feel unconfident, and ultimately they will lose interest in learning English in a long run. There is also a problem in the attitude of students in higher vocational colleges, and many students often choose to give up while encountering English learning difficulties. They understand English learning requires the day-to-day accumulation, but can't be finished in one say. They know they can make a success as long as they can keep perseverance in the right way, even though the learning can't be done in a short term. However, they do not adhere to the learning objective eventually.

\section{The impact on interest}

A survey found that the students' interest in learning English would also affect their pronunciation and command of English words. The result was that the interest was in direct proportion to the degree of pronunciation accuracy. In other words, the pronunciation was more accurate if the students were more interested in English learning. Furthermore, it was found that female students were more interested than male students in English learning, indicating interest was correlated with gender and gender could play a certain impact on English learning and pronunciation.

\section{The impact from knowledge reserves and pronunciation habits}

Some college students' pronunciation about10 English words with "t" at both ends were briefly analyzed and the result is as follows.

(1) Talent [U.K] ['tælənt]

There was nothing wrong about pronouncing "talent" and students could accurately read it.

(2) Target [U.K] ['ta:git]

There was nothing wrong about pronouncing "target" and only a few students pronounced [t] as [st].

(3) Trumpet [U.K] ['tr $\Lambda$ mpit]

The main problem in pronouncing "trumpet" was that some students $(20 \%)$ did not pronounce [I], and the rest could pronounce it well, as shown in Fig.1.

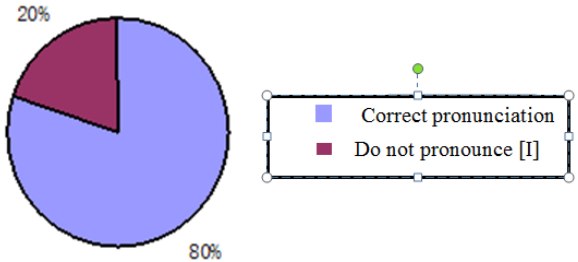

Fig. 1 the pronouncing effect of "trumpet" 
(4) Tattooist [U.K] [tə'tu:Ist]

Unexpectedly, almost $36 \%$ of the students didn't know how to pronounce "tattooist" (a word in high school vocabulary), about $20 \%$ did not pronounce [I], but the rest $50 \%$ could. Most students did not accurately grasp the stress, and they were supposed to stress [u:], but pronounced [I] finally. Only a very few students could pronounce "tattooist" accurately, as shown in Fig.2.
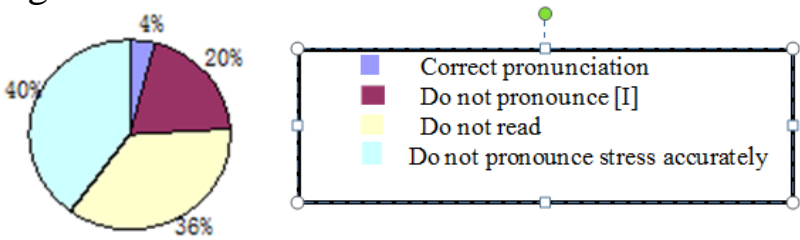

Fig.2 the pronouncing effect of "tattooist" (5) Technologist [U.K] [tek'nplədzIst] $78 \%$ of the students pronounced [ə] as [I], possibly because of the impact from the previous inaccurate pronunciation or unpracticed phonetic command, as shown in Fig.3.
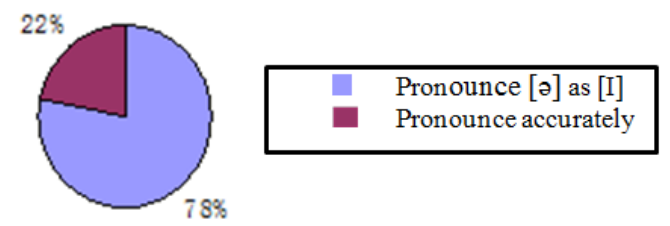

Fig.3 the pronouncing effect of "technologist" (6) Throughput [U.K] ['Oru:pot]

$90 \%$ of the students still pronounced lisping [ $\theta]$ for "th" as non-lisping [s], as shown in Fig.4.
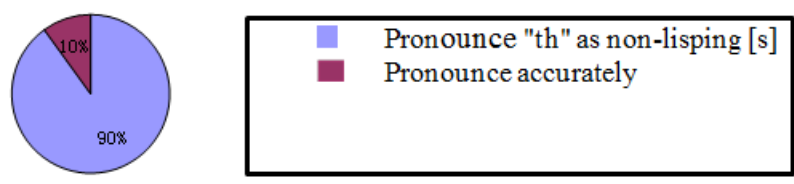

Fig.4 the pronouncing effect of "throughput" (7) Taxidermist [U.K] ['tæksId3:mist]

About $50 \%$ of the students did not pronounce "taxidermist". $8 \%$ pronounced [si] as [s]; 30\% did not accurately grasp long/short syllable and stress, and they pronounced stress [sI] as light syllable, but light [3:] as stress and short syllable; a considerable part of students pronounced [3:] as [e], as shown in Fig.5.

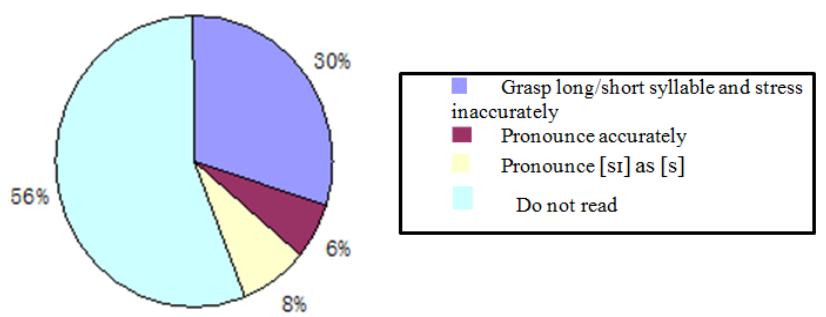

Fig.5 the pronouncing effect of "taxidermist" (8) Tantamount [U.K] ['tæntəmaont] $30 \%$ of the students did not pronounce "tantamount"; 10\% pronounced stress [æn] as light syllable, but pronounced light [ə] as stress; about $5 \%$ pronounced stress on [av], as shown in Fig.6.

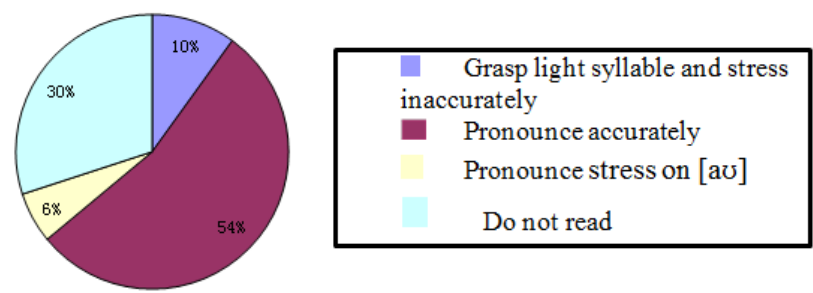

Fig.6 the pronouncing effect of "tantamount" (9) Transport [U.K] ['trænspo:t]

Almost $90 \%$ of the students did not transform voiceless consonant [p] to [b], because they did get a full understanding of the phonetic symbols and did not know the change of pronouncing rules, as shown in Fig.7.
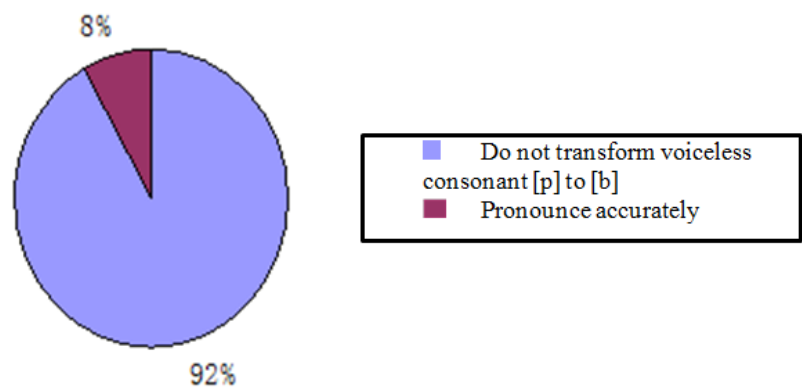

Fig.7 the pronouncing effect of "transport" (10) Transcendent [U.K] [træn'sendənt] About $40 \%$ of the students pronounced "transcendent" well and their pronunciation had no problems; only a few students pronounced [sen] as [sekən]. 


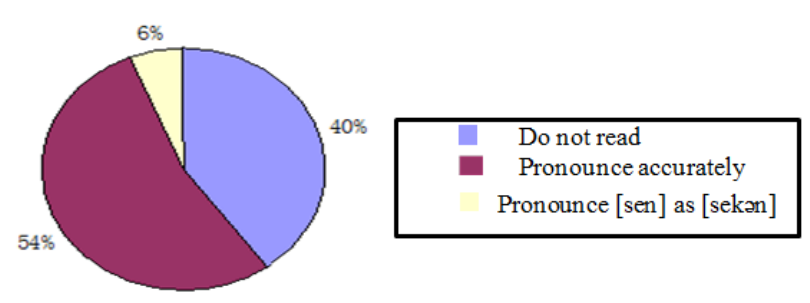

Fig.8 the pronouncing effect of "transcendent"

The survey found that the students' English learning as well as their command of pronunciation was not always proportional to the educational years. The students were consulted about how they read and recited English vocabularies and most said they often memorized mechanically words and phrases, but ignored the pronunciation of the words. This was not helpful for improving the efficiency of word pronunciation and recitation. Memorizing words, reciting articles and imitating the tapes are actually very important for English pronunciation, and then, auditory, vision and oral ability can be mobilized at the same time. As a result, the pronunciation of the words is accurate naturally. Moreover, the spelling accuracy of the words marked according to the pronunciation will be higher.

\section{Feasible countermeasures}

\subsection{More listening and frequent imitation}

In English learning, attention must be paid to stress, intonation emphasis, and the correctness of the pronunciation way. Many mistakes of English learners source from the improper imitation methods or the incorrect objects of the imitation. Therefore, imitation is necessary, and the imitated objects as well as the selectivity of the contents must be seriously selected.

Great importance to the improvement of the quality of teachers is an important part. This is because there are problems in the pronunciation by some English teachers. The decontextualized pronunciation training materials for students to do mechanical exercises must be less frequently used as far as possible, while question and answers in role play must be imitated more frequently, and the teaching experience can be shown according to the recording materials. The occurrence of errors is inevitable in the process of English teaching, and therefore, the impact of dialects on the pronunciation of English learners is not likely to completely eliminate. Students are very difficult to make self-discovery and self-correction according to their own pronunciation mistakes, so it is necessary for teachers to timely correct the pronunciation mistakes of students.

\subsection{Strengthening the training of the mandarin}

Dialogue and discussion in the research and analysis found that the students speaking the mandarin more accurately pronounced English words more accurately. At ordinary times, therefore, students must communicate with people in mandarin as much as possible. In some cases, some teachers often feel helpless to correct the pronunciation errors of students, especially the errors caused by dialect tones. Actually, these teachers need to pay attention to the student's mandarin pronunciation. The accurate mandarin pronunciation can let students get twice the result with half the effort in English pronunciation.

\subsection{Establishing a pronunciation file}

Teachers can establish a pronunciation file for each student and record the pronunciation problems of each student. For example, the students, coming from Jiaozuo, cannot clearly distinguish between [n] and [1], between [h] and [f] and so on. Teachers must correct pronunciation for students in a targeted way, and also urge students to pay attention to make conclusions and avoid making the same mistake next time. In the teaching method, teachers can also apply modern educational technology to the pronunciation teaching. English recording and audio-video materials have created good conditions for English learning, and voice materials can be especially effective. The introduction of multimedia teaching means to the audio classes can make the classroom 
atmosphere active and arouse the enthusiasm of students for learning. In addition to creating a relaxed and harmonious classroom language environment, the teaching of English pronunciation can also be extended to some extracurricular activities.

\section{Conclusion}

English pronunciation learning doesn't happen overnight. Students are required to learn and research, and also pay attention to the collection of their own pronunciation mistakes at any time. Meanwhile, they need to make diligent practice and gradual progresses, aiming to better command English pronunciation.

\section{References}

[1] Flege, J.E., Using Visual Information to Train Foreign-Language Vowel Production. Language Learning, 1988, 38(3): 365-407.

[2] Flee, J.E., English Vowel Production by Dutch Talkers: More Evidence for the "Similar" vs. "New" Distinction. Second Language Speech: Structure and Process, 1997: p. 11-52.

[3] Shou LIN, Lijia WANG, et al. Phonetics Tutorial. Peking University Press, 11/1/1992.

[4] Zhilei YIN. The Influence of Context on English Consonants [J]. Basic Education of Foreign Language Teaching Research, 2/15/2003.

[5] Weimin HU. Discussion on English Consonants $[\mathrm{J}]$. Foreign Language Journal (Journal of Heilongjiang University), 1995 (10).

[6] You WANG. Study on the Cases of Chinglish Consonant Pronunciation Characteristics [J]. Journal of Sichuan College of Education Institute, 2007

(6). 